\title{
Os Magalhães e a fundação de hospitais em Ponte da Barca (1560-1590)
} The Magalhães family and the establishment of hospitals in Ponte da Barca (1560-1590)

\section{Alice Borges Gago ${ }^{1}$}

Resumo: Partindo do estudo de um arquivo de família, o Almada e Lencastre Bastos, à guarda da Biblioteca Nacional de Portugal, o artigo apresenta novos dados sobre a instituição de hospitais de assistência a pobres e peregrinos quinhentistas, em Ponte da Barca, pela família Magalhães, senhores da mesma localidade.

Palavras-Chaves: Hospital; assistência; peregrinos; Ponte da Barca.

\begin{abstract}
This article presents new data on the foundation of $16^{\text {th }}$ century hospitals for the poor and pilgrims by the Magalhães family, lords of Ponte da Barca, based on the study of a family archive, the Almada and Lencastre Bastos fonds, held by the National Library of Portugal.
\end{abstract}

Keywords: Hospital; assistance; pilgrims; Ponte da Barca.

${ }^{1}$ Instituto de Estudos Medievais, Universidade Nova de Lisboa. ORCID ID: http://orcid.org/0000-0003-3680-1195. 


\section{0 fundo Almada e Lencastre}

\section{Bastos: breve história custodial}

O fundo Almada e Lencastre Bastos (ALB), depositado na Biblioteca Nacional de Portugal (BNP) desde 1974, abarca cronologicamente os séculos XIV a XX e deve a sua denominação ao apelido do último proprietário, João de Almada e Lencastre Bastos, que propôs a sua venda ao Estado português. Este fundo integra dois cartórios: o dos viscondes de Vila Nova de Souto del $\operatorname{Rei}^{2}$ e o do conde da Feira ${ }^{3}$. Após ter falecido sem descendência, em 1827, Miguel Forjaz Coutinho, conde da Feira desde $1820^{4}$, os seus bens e arquivo foram herdados por sua irmã, Maria Joana Forjaz Coutinho, e reunidos (apenas fisicamente) no cartório de Souto del Rei por via do casamento desta com o terceiro visconde,João José de Almada Velho e Lencastre.

O ALB manteve-se na família até que,em 1957, João de Almada e Lencastre Bastos pretendeu vender o arquivo (ANTT, Instituto Superior das Bibliotecas e Arquivos, cx. 329, proc. 274; ANTT, Arquivo do arquivo, n. ${ }^{\circ} 331$, cx. 146, proc. 91), tendo então sido avaliado e posteriormente vendido à BNP pelos seus familiares em 1974.
A inventariação sistemática do ALB permitiu identificar a documentação referente a um vasto conjunto de famílias pertencentes às elites de várias localidades portuguesas que, até agora, apenas conhecíamos de outros fundos arquivísticos. Estes não eram, no entanto, os documentos produzidos e conservados pelos seus produtores ou destinatários e pelos seus familiares ao longo de séculos - os arquivos familiares, sobre os quais a arquivística e a historiografia têm vindo a debruçar-se nos últimos anos, num movimento conhecido como tournant documentaire (Morsel, 2008; 2013). Esta perspetiva de olhar os arquivos tem sido aplicada, entre outras, pelas historiografias francesa (Contamine e Vissière, 2010), espanhola (García Aser e Lafuente Úrien, 2000) e pela portuguesa (Rosa, 2009: 9-42; A. M. Silva, 1997: 51-106), com o objetivo de estudar a produção informacional das instituições e a sua transformação em arquivos, complementando esse estudo com dados reunidos em várias fontes, o que permite caracterizar historicamente as instituições e construir modelos orgânicos para o tratamento da documentação, analisando, contextualizando e interpretando as práticas

\footnotetext{
${ }^{2}$ Cujo primeiro titular foi Francisco de Almada e Mendonça, e posteriormente reconhecido no seu sobrinho, António José de Almada e Melo, e nos descendentes deste, até ao quarto titular (J. M. Silva, 1917: 146-152; Pinto, 2012: 309).

${ }^{3}$ A primeira representação do título de conde da Feira terminara com o falecimento, em 1700, sem descendência, de Fernando Forjaz Pereira Pimentel de Meneses e Silva, pelo que a tentativa de recuperação do título pelos seus parentes originou um longo processo, que incluiu, entre outras diligências, a forja de vários documentos, numa tentativa de justificar a pretensão ao título (Pinto, 2012: 310-311; Conceição, 1720).

${ }^{4}$ A 13 de maio de 1820 (Pinto, 2012: 310; Fuente, 2011).
} 
arquivísticas, «seguindo todo o percurso da informação e compreendendo as mutações a que o tempo a sujeitou» (Rosa, 2017: 550), perspetiva de investigação que tem dado origem a diversos estudos 5 .

A inventariação do ALB permitiu-nos detetar a produção documental pertencente à família Magalhães, senhores da Nóbrega. No que concerne a esta família, o acervo diz respeito não só à compra e venda de propriedade, a sentenças judiciais, mas também, e sobretudo a partir de meados do século XVI, à transmissão de bens de morgadio, uma vez que a família adotou o modelo reprodutivo vincular (Cunha e Monteiro, 2010: 65; Monteiro, 2001: 19, 33). Esse facto originou um aumento da massa documental - os documentos eram utilizados como provas de posse, defesa de direitos, partilhas de bens, habilitação a heranças e sucessão, em suma, utilizados na gestão do património e da casa, pelo que era fundamental o acesso e a recuperação facilitada dos mesmos (Rosa, 2012: 580-582; Borja de Aguinagalde, 2013: 27; De Vivo, 2010: 231-248; Gómez Vozmediano, 2007: 137; Head, 2007: 320), através de róis ou inventários.
Registados desde finais do século XV (Gago, 2019:259-260), os inventários constituem uma etapa na estruturação das famílias das elites iniciada no século XVI, com a criação dos vínculos, e posteriormente no contexto político saído da Restauração, o «que contribuiu de forma determinante para a consolidação do conceito de Casa que começou a emergir em Setecentos» (Rodrigues e Silva, 2012: 614) e levou à organização e reorganização de cartórios de numerosas famílias nobres ${ }^{6}$, tendo tido o seu golpe final com a profunda mudança política, económica e social que o fim do sistema vincular (Coelho, 1980: 111) trouxe às famílias detentoras de vínculos, fazendo com que muitos deles deixassem de ter qualquer utilidade de prova de bens e mercês, a qual lhes deu origem e garantiu a sua integridade durante vários séculos.

\section{Os Magalhães, senhores da Nóbrega}

São vários os autores ${ }^{7}$ que, apoiados nas genealogias de Felgueiras Gaio, D. António de Lima, nas Inquirições de 1288 e no Livro de linhagens do século XVI (ANTT, Genealogias manuscritas, 21-F-08; Portugaliae..., 2012; Livro de linhagens do século XVI, 1956), têm publicado estudos sobre a família

\footnotetext{
${ }^{5}$ Dentre os quais destacamos os trabalhos em Arquivística Histórica de Nóvoa (2016), Sousa (2017), Leme (2018) e Gago (2019).

${ }^{6}$ Como os cartórios da casa de Bragança, dos condes de Povolide, da casa de Melo, entre tantos outros (Páscoa, 2015: 53-57; Rodrigues e Silva, 2012: 614-617; Gago, 2015: 162-163).

${ }^{7}$ Nomeadamente Villas Boas (1998) e Soveral (s. d.). Num registo diferente, com gerações mais tardias, sobre a fundação e provedoria da Misericórdia de Ponte da Barca e apoiada em documentação da referida Misericórdia, veja-se o trabalho de Pereira (2008).
} 
Magalhães, a sua origem e os seus elementos. Apoiados em diferentes bibliografias, os resultados são, naturalmente, discordantes se Villas-Boas (1998: 25), baseado em Felgueiras Gaio (1939: 161), atribui a origem dos Magalhães em Portugal à chegada, em 1245, de Afonso Vaz, cavaleiro bolonhês, companheiro de D. Afonso, conde de Bolonha, já Abranches de Soveral (s. d.) sugere, apoiado nas Inquirições, que a mais antiga referência a um Magalhães se refere a Rui Fernandes de Magalhães, «senhor da honra da quintã da Torre de S. Martinho de Magalhães (hoje a freguesia de Paço Vedro de Magalhães, no concelho de Ponte da Barca) e do couto de Fontarcada (Póvoa de Lanhoso)» (s. p.).

Segundo uma árvore genealógica manuscrita existente no ALB (BNP, ALB, Roma, cx. 76, cap. 1 , doc. n. n.), realizada posteriormente a 1705, data de nascimento de João Manuel de Meneses, que a terá encomendado para registar a sua ascendência relativamente à família Magalhães, a linhagem grafada é a mesma seguida por Felgueiras Gaio no Nobiliário, o que poderá sugerir duas hipóteses: que a linha sucessória apresentada por Felgueiras Gaio está correta, ou que a árvore em questão foi elaborada segundo a mesma fonte.

Apoiando-nos nos documentos que nos chegaram desta família, podemos afirmar que o primeiro elemento do qual registamos documentos no ALB é Afonso Rodrigues de Magalhães, senhor do castelo da Nóbrega ${ }^{8}$, outorgado por D. Fernando no ano de 1367 (ANTT, Chancelarias régias, D. Fernando, liv. 1, fl. 7), que também lhe concedeu, em 1372, Vila Chã e Larim pela sua participação no contexto de guerras fernandinas com Castela (ANTT, Chancelarias régias, D. Fernando, liv. 1, fl. 111). Segundo os autores acima referidos, terá casado com Teresa Freire de Andrade, filha bastarda do Mestre da Ordem de Cristo, Nuno Freire de Andrade Sotomaior ${ }^{9}$. Em 1363, estava casado com Maria Fernandes, filha de Martim Esteves e Catarina Ferreira (BNP, ALB, Roma, cx. 99, n. ${ }^{\circ}$ 150, cap. 2, cota antiga: M 99 N 19; cx. 59, fls. 145-146 [cópia]). Teve pelo menos dois filhos: Gil Afonso de Magalhães e Inês Afonso (BNP, ALB, Roma, cx. 114I, n. 187, cap. 3, cota antiga: M 114 N 45).

\footnotetext{
${ }^{8}$ A terra da Nóbrega ocupa a zona entre Ponte da Barca e a fronteira do Lindoso, sendo delimitada a norte pelo rio Lima, a oeste pela terra de Penela, a sul pelas terras de Regalados e do Bouro, e a este pela Galiza. No final do reinado de D. Afonso Henriques, surgiu na região Ourigo Ourigues, a quem o rei doou dois casais por ter construído o castelo da Nóbrega. O seu filho, Pedro Ourigues, acompanhou o príncipe D. Afonso no seu exílio em Bolonha, esteve ao seu lado no tratado de Paris e ajudou-o nos primeiros anos de luta pela posse do reino português, durante a guerra civil com D. Sancho II. A família perdeu o poder político na região e abandonou a mesma durante o século XIII para se instalar no Alentejo, mais precisamente em Portel, já na geração do neto de Ourigo Ourigues, João Peres de Aboim (Abreu, 1910: 375-376; Coelho, 1990: 170-198; Mattoso, 1985: 222-223).

${ }^{9}$ Nomeado por D. Pedro I em 1357 como Mestre da Ordem de Cristo. Sobre a personagem, ver J. P. M. Silva (2010).
} 
D. João I confirmou a Gil Afonso de Magalhães os bens de seu pai e doou-lhe, em $1387^{10}$, o couto de Fonte Arcada $^{11}$ e a terra de Lindoso. Este casou, mais ou menos por essa data, com Inês Vasques ${ }^{12}$, aia da rainha D. Filipa de Lencastre (ANTT, Leitura Nova, Além Douro, liv. 4, fl. 19; ANTT, Chancelarias régias, D. Afonso V, liv. 10, fls. 28v.-29; BNP, ALB, Enc., cx. 11A, cap. 3, cota antiga: M 104 N 6, fl. 2), a qual adquiriu, em 1389, o couto do Souto de Rebordões pelo montante de cinquenta libras (BNP, ALB, Enc., cx. 11A, cap. 3, cota antiga: M 104 N 6, fl. 2; Chancelarias portuguesas: D. Duarte, 1998, doc. 1124: 346-347; ANTT, Chancelarias régias, D. Afonso V, liv. 10, fls. 28v.-29). O casal teve pelo menos três filhos: Afonso, João e Fernão. O primogénito, Afonso de Magalhães, herdou os senhorios dos pais e em 1454 fez doação ao seu irmão João de Magalhães do Souto de Rebordões (BNP, ALB, Enc., cx. 11A, n. ${ }^{\circ} 3$, cap. 3, cota antiga: M 104 N 6). Tendo falecido Afonso de Magalhães, sem descendência (BNP, ALB, Enc., cx. 11A, n. 3 3 , cap. 3, cota antiga: M 104 N 6), a sucessão dos restantes bens recaiu sobre João de Magalhães, fidalgo da casa do Duque de Bragança (ANTT, Leitura Nova, Além Douro, liv. 4, fl. 19), tendo recebido de
D. Afonso $V$ a confirmação da terra da Nóbrega em 1458 (ANTT, Leitura Nova, Além Douro, liv. 1, fls. 244v-245; Duarte, 1996: 383; Moreno, 1980: 1049, nota 2).

A jurisdição da terra da Nóbrega e alcaidaria do seu castelo e o Souto de Rebordões constituíram o núcleo de poder que os varões primogénitos transmitiram ao longo de várias gerações, o que lhes permitiu afirmar e consolidar o poder político, militar, jurisdicional e económico da família nesta zona do país.

Para isso contribuíram não só as ligações clientelares com a casa de Bragança, da qual alguns elementos da família eram escudeiros e fidalgos ${ }^{13}$, ou com a casa de Viseu ${ }^{14}$, mas também as alianças matrimoniais que foram estabelecendo com famílias do mesmo nível económico e social - João de Magalhães I casou com Isabel de Sousa, neta de Lopo Dias de Sousa, Mestre da Ordem de Cristo (A. M. Silva, 1997: 9-126); Gil de Magalhães casou duas vezes, ambas com senhoras de famílias nobres: Maria de Meneses, filha de Rui Gomes da Silva, alcaide de Campo Maior, e Isabel de Meneses, filha de Gonçalo Nunes Barreto, alcaide-mor de Faro e senhor de Quarteira, e de

\footnotetext{
${ }^{10}$ Carta de doação da terra de Lindoso de 16 de maio de 1387. Chancelarias portuguesas: D. João I, 2005, doc. 3: 13.

${ }^{11}$ Carta de confirmação do couto de Fonte Arcada de 9 de junho de 1387. Chancelarias portuguesas: D. João I, 2005, doc. $286: 162$.

${ }^{12}$ Algumas genealogias afirmam que Inês Vasques era filha do escudeiro Álvaro Gil de Urró. No entanto, é precisamente a este senhor que Inês Vasques compra o Souto de Rebordões em 1389. Chancelarias portuguesas: D. Duarte, 1998, doc. 630: 59-60; doc. $1124: 346-347$.

${ }^{13}$ Como, por exemplo, João de Magalhães I. ANTT, Leitura Nova, Além Douro, Liv. 4, fl. 19.

${ }^{14}$ Como foi o caso de Gil de Magalhães. ANTT, Leitura Nova, Além Douro, liv. 4, fl. 3.
} 
Isabel Pereira, filha do governador da casa do Infante D. João15; João de Magalhães II casou com Leonor da Silva, filha de Fernão de Castro, alcaide-mor de Melgaço; Manuel de Magalhães casou com Margarida da Silva, filha de Leonel de Abreu, quinto senhor de Regalados e alcaide-mor da Lapela; António de Magalhães casou com Isabel de Meneses, sua prima. Os casamentos endogâmicos foram, como em tantas outras famílias da nobreza portuguesa, uma prática nesta família. Deles são exemplo este último a que nos referimos, mas também entre Constança e Francisco de Magalhães, João e Inês de Magalhães.

Até 1560, a posse da terra da Nóbrega e Souto de Rebordões constituíram os bens prestigiantes e transmissíveis ao primogénito da linhagem, mas a partir desse ano, data de instituição de uma capela na Igreja de S. João de Ponte da Barca (BNP, ALB, Roma, cx. 81, n. ${ }^{\circ} 92$, cap. 1, doc. n. n.) por Manuel de Magalhães e Margarida da Silva, esse paradigma alterou-se, com a introdução de um novo elemento e modelo de transmissão de património - o modelo de sucessão vincular. Com efeito, após 1561 , começam a surgir na família novas regras de sucessão no património familiar. Se até então o bom serviço régio era garantia da confirmação dos bens da coroa, a gestão e transmissão da administração do património vinculado obedecia a outras regras - aquelas que haviam sido impostas pelos instituidores. E bastava que uma delas não fosse cumprida para que alguém fosse afastado da administração do vínculo, como aconteceu com António Magalhães de Meneses. Por este motivo, a administração da capela não foi entregue ao primogénito como seria de esperar, mas sim a um filho segundo - Matias da Silva -, que a transmitirá, por falta de sucessão legítima ${ }^{16}$, a um sobrinho da sua cunhada Isabel de Meneses - Bento da Silva Meneses (BNP, ALB, Roma, cx. 81, n. ${ }^{\circ}$ 92, cap. 1, doc. n. n.). Em 1665, era um sobrinho deste, Manuel da Silva Meneses, abade de Santo André de Guilhadeses, quem administrava os bens da capela, embora outro documento refira que Constantino de Meneses, filho de António de Magalhães de Meneses, «tomou conta do casco da capella de que não foi excluído» (BNP,ALB,ANTT, cx. 19, doc. 27), indicação de que os bens da capela foram «desanexados» da capela «física», se assim o podemos dizer. Não podendo ser administrador da capela dos pais, António e Isabel fundaram, por sua vez, em 1576, uma capela da invocação da Madre de Deus, na Quinta da Boavista (BNP, ALB, Roma, cx. 91A, n. ${ }^{\circ} 122$, cap. 1, cota antiga: M 38 N 57).

A implementação do modelo de sucessão vincular sofreu alguns reveses nesta família.

\footnotetext{
${ }^{15}$ Sobre Gonçalo Nunes Barreto, veja-se Santa (2018: 12-35).

${ }^{16}$ Segundo Gaio (1939: 163, 179), Matias da Silva, escolar, teve apenas filhos ilegítimos.
} 
Para além deste atropelo inicial, as gerações seguintes foram também marcadas por quebras de varonia e primogenitura. Constantino de Magalhães de Meneses ${ }^{17}$ casou com Isabel de Aragão, mas o seu primogénito, António de Magalhães e Meneses, faleceu, cerca de 1670 , sem descendência, tendo os bens sido transmitidos à irmã Joana Manuel de Magalhães (BNP, ALB, Enc., cx. 11A, cap. 3, cota antiga: M 104 N 6). Esta casou com Afonso de Meneses, mestre-sala de D. João IV ${ }^{18}$ (BNP, ALB, Enc., cx. 11A, cap. 3, cota antiga: M 104 N 6), filho de Fradique de Meneses e de Isabel Henriques ${ }^{19}$.

A linhagem dos Magalhães, agora associada à dos Meneses, prosseguiu com os filhos do casal Joana e Afonso: Fradique António de Magalhães e Meneses, casado com Jerónima Barreto Corte Real, filha de Fernão Nunes Barreto, morgado de Freiriz, e João Manuel de Meneses. Nenhum dos vários filhos do primeiro casal teve descendência ${ }^{20}$, pelo que coube o seguimento da família ao irmão de Fradique - João Manuel de Meneses, casado com Francisca Luísa Ferreira de Mendonça, filha de Francisco Ferreira Furtado de Mendonça, morgado de Argemil, e de Maria de Mendonça Antas, filha de Gaspar dos Reis Dantas. O filho deste casal, Francisco Furtado de Mendonça e Meneses, casou com Mariana Luísa de Valadares, filha de João de Valadares Carneiro, acrescentando aos morgadios que já detinha o morgadio dos Valadares. Dos filhos deste último casal, foi o secundogénito João Manuel de Meneses quem herdou os morgadios detidos pela família. Nascido em Ponte de Lima, em 1705 (BNP, ALB, Roma, cx. 76, cap. 1, doc. n. n.), local onde, desde pelo menos do tempo do seu avô, a família veio a instalar-se no «arrabalde além da ponte», casou com Maria Rosa de Meneses, filha do almotacé-mor do reino, João Gonçalves da Câmara Coutinho e de Luísa de Meneses, dama do paço. Dos filhos do casal, foi a primogénita Mariana Luísa da Trindade e Meneses quem herdou o património da casa. Nascida em 1727, foi apenas aos 30 anos que casou com Tristão da Cunha de Mendonça e Meneses, filho do vedor da casa da rainha D. Mariana de Áustria, Carlos José Bento de Meneses, também ele senhor de vários morgadios ${ }^{21}$.

\footnotetext{
${ }_{17}^{17}$ Viu os bens da coroa confirmados em 1591 e em 1626. BNP, ALB, Enc., cx. 11A, cap. 3, cota antiga: M 104 N 6.

${ }^{18}$ Foi ainda capitão-mor de Monção (Gaio, 1941: 27).

${ }^{19}$ Filha de Fernão Nunes Barreto, pertencente ao subsistema de informação Ferraz, como veremos adiante. BNP, ALB, Roma, cx. 76, cap. 1, doc. n. n.

${ }^{20}$ Afonso de Magalhães e Meneses, falecido antes de 1740, e João Luís de Meneses, que nessa mesma data requereu a D. João V que lhe fizesse mercê da Nóbrega e Souto de Rebordões e dos padroados e tenças. ANTT, Chancelarias régias, D. João V, liv. 9, fl. 240v.

${ }^{21}$ Segundo Gaio (1941: 29), era morgado da Patameira e Caparica.
} 
Por questões de partilhas, à morte do avô João Manuel de Meneses, ocorrida em 1769 (BNP, ALB, Roma, cx. 113A, cap. 1, doc. n. n.), e do tio deste, João Luís de Meneses ${ }^{22}$, gerou-se uma questão sucessória entre as irmãs Mariana Luísa e Luísa Antónia de Magalhães e Meneses, casada com Diogo Pereira Forjaz Coutinho Barreto de Sá e Resende, governador da Madeira entre 1781 e 1798 (BNP, ALB, Roma, cx. 81A, n. ${ }^{\circ}$ 91, cap. 1, cota antiga: D 1 M 12 $N$ 113). A questão apenas veio a resolver-se entre os filhos de ambas, os primos João Manuel de Meneses e Miguel Pereira Forjaz Coutinho, e encerrar-se pela morte do primeiro, sem sucessão, em 1819 (BNP, ALB, Enc., cx. 54B, cap. 2, doc. n. n.). Miguel Pereira Forjaz, filho de Diogo Forjaz, foi o herdeiro do primo, mas devido ao seu falecimento, ocorrido em 1827, sem descendência, todo o património e documentos foram herdados pela irmã, Maria Joana do Monte Forjaz Câmara Coutinho, casada com o terceiro visconde de Vila Nova de Souto del Rei, e por esta transmitidos aos seus descendentes até à sua venda, em 1974, à Biblioteca Nacional de Portugal, como anteriormente mencionámos.

Dos elementos referidos na apresentação da família Magalhães, foram Manuel de Magalhães e o seu filho António de Magalhães os instituidores de dois hospitais em Ponte da Barca na segunda metade do século XVI.

\section{Manuel de Magalhães e a fundação do hospital de pobres - 1560}

Filho de João de Magalhães II e de Leonor da Silva, Manuel de Magalhães (flor. 152423 $-1581^{24}$ ) casou com Margarida da Silva ${ }^{25}$ (flor. 154026-159327) cerca de 1540 (BNP, ALB, Roma, cx. 60, fls. 118-124), tendo sido pais de António de Magalhães e Meneses, Leonor da Silva e João de Magalhães III.

Cavaleiro fidalgo da casa real ${ }^{28}$, foi-lhe confirmada por D. João III a posse da terra da Nóbrega, em 1528 (BNP, ALB, Roma, cx. 58, fl. 168; ANTT, Chancelarias régias, D. João III, liv. 16,

\footnotetext{
22 O testamento de João Luís de Meneses data de 2 de julho de 1764. BNP, ALB, Roma, cx. 113A, cap. 1, doc. n. n.

23 BNP, ALB, Enc., cx. 50, n. ${ }^{\circ}$ 23, cap. 3, cota antiga: M 40 N 35.

${ }^{24}$ BNP, ALB, Enc., cx. 11A, cap. 3, fl. 3; BNP, ALB, Roma, cx. 58, fl. 298.

${ }^{25}$ Filha de Leonel de Abreu e Lima, senhor de Regalados, e de e de Maria de Sousa. Meia-irmã de Lopo Gomes de Abreu e Lima, que era filho do mesmo pai, e de Maria de Noronha. Recebeu o dote de 18.000 dobras em 4 de abril de 1540, sendo uma parte paga em terras e a outra em dinheiro, da qual 6000 dobras por arras. BNP, ALB, Roma, cx. 60, fls. 118-124.

${ }^{26}$ BNP, ALB, Roma, cx. 60, fls. 118-124.

${ }^{27}$ BNP, ALB, Enc., cx. 11A, n. ${ }^{\circ}$ 3, cap. 1, cota antiga: M 106 N 16.

${ }^{28}$ Com moradia de 2437 reais (Sousa, 1742: 797).
} 
fl. 84) ${ }^{29}$, da qual foi nomeado alcaide-mor do castelo, em $1572^{30}$ e, em 1529, do Souto de Rebordões (BNP, ALB, Enc., cx. 11A, cap. 3, cota antiga: M 104 N 6, fl. 2).

Em relação à sua atividade militar, sabemos que esteve em Ceuta cerca de 1544, acompanhado por dez homens de sua casa, para ajudar a defender a cidade da armada do turco ${ }^{31}$. Ficou nesta praça algum tempo ao serviço da coroa (BNP, ALB, Roma, cx. 58, fls. 177-178) e só regressou quando o rei dispensou os morgados e comendadores ${ }^{32}$. Entre 1572 e 1574, prestou auxílio ao rei ao enviar homens para combater os turcos ${ }^{33}$ em Tânger.

Em 1560, instituiu com a sua mulher uma capela na Igreja de S. João, em Ponte da Barca (BNP, ALB, Roma, cx. 81, n. ${ }^{\circ}$ 92, cap. 1, doc. 1; cap. 2, doc. 10), para a qual nomeou para administrador o seu filho mais velho, António de Magalhães. No ano de 1561, o casal adicionou nova cláusula referente à administração da mesma, alterando a obrigatoriedade de o administrador dotar a capela com a sua terça para comprar bens de raiz, no valor de 24.000 reais, nos primeiros dois anos do seu mandato ou, em alternativa, dotar a mesma com os seus próprios bens (BNP, ALB, Roma, cx. 81, n. ${ }^{\circ}$ 92, cap. 1, docs. 2 e 3). Em 15 de setembro de 1573 , os instituidores anularam a nomeação de António de Magalhães, por este lhes ter desobedecido e casado contra a vontade dos pais com Isabel de Meneses (BNP, ALB, Roma, cx. 81, n. ${ }^{\circ}$ 92, cap. 1, doc.). A quebra de uma das regras de sucessão do morgadio - o casamento com consentimento dos pais - levou ao afastamento da sucessão na administração da capela, a qual passou para um seu filho mais novo (BNP, ALB, Roma, cx. 81, n. ${ }^{\circ}$ 92, cap. 1 , doc. $\left.1^{34}\right)$, Matias da Silva, mestre-

\footnotetext{
${ }^{29}$ No entanto, já em 1527, no arrolamento da população do Entre-Douro-e-Minho, este surge já como senhor do concelho da Nóbrega. Ver Freire (1905: 244).

${ }^{30}$ Tinha usado da jurisdição e privilégios de alcaide-mor do castelo, quando a mesma the foi retirada por sentença de 1556 e de 1569. ANTT, Gavetas, gav. 10, mç. 8, n. ${ }^{\circ} 4$; gav. 13 , mç. 4, n. ${ }^{\circ} 11$. Em 1572, foi novamente nomeado alcaide-mor, sendo a doação apenas em sua vida, com todas as rendas, tributos, podendo apresentar o alcaide pequeno. Tomou posse em 24 de novembro de 1573. BNP, ALB, Roma, cx. 58, fls. 166-172.

${ }^{31}$ A partida devia efetuar-se no Porto até ao fim de abril de 1544, porque nesse mês as galés já podiam navegar. Não devia levar cavalos, nem fazer despesas acima daquelas estritamente necessárias por impedimento da fazenda real. Foi autorizado a levar mercadorias que poderia vender em Ceuta, nos armazéns do rei, pelo preço que os bens custaram ao rei levá-los lá. Se não tivessem armas, poderiam pedi-las no armazém de Ceuta, mas estas teriam de ser devolvidas. BNP, ALB, Roma, cx. 58, fl. 154.

32 O mesmo também consta de certidão pedida por António de Magalhães, seu filho, em 1581. BNP, ALB, Roma, cx. 58, fls. $227-228$.

33 Os homens deviam ser pagos de soldo e mantimento à custa de Manuel de Magalhães pelo tempo de três meses. BNP, ALB, Roma, cx. 58, fls. 155-159.

$34 \mathrm{O}$ documento tem essa cláusula sublinhada a vermelho no fl. 4v. Manuel de Magalhães e sua esposa determinam que o filho não suceda, nem os descendentes dele.
} 
-escola no Cabido da Guarda ${ }^{35}$. Este, falecido sem herdeiro filho de casamento legítimo (Gaio, 1939, 179) - uma outra condição dos instituidores - e na impossibilidade de a transmitir ao sobrinho Constantino de Magalhães, filho de António de Magalhães, nomeou Bento da Silva Meneses ${ }^{36}$, filho de Jerónimo Barreto de Meneses e sobrinho da cunhada Isabel de Meneses. Não sendo descendente direto de António de Magalhães e Isabel Meneses, era, pelo menos, da linhagem (BNP, ALB, Roma, cx. 81, n. ${ }^{\circ}$ 92, cap. 1, doc.n. n.).

No documento instituidor da capela, refere-se ainda que Manuel de Magalhães tinha intenção de dotar a Misericórdia de Ponte da Barca com o excedente das rendas dos bens vinculados. Esta indicação permite, com segurança, afirmar que a Misericórdia de Ponte da Barca já existia nesta data, 1560, recuando em cerca de 24 anos a data até agora conhecida, de 1584, data do primeiro documento pertencente ao Arquivo da Misericórdia de Ponte da Barca, como é referido por alguns autores (Costa, 1998: 104; Goodolphim, 1897: 349; Portugaliae Monumenta Misericordiarum,
2006: 252). De referir ainda que um outro documento, datado de 1548, refere a propósito de umas confrontações de propriedade adquirida pela família Magalhães que esta se encontrava na rua pública em frente a um hospital (BNP, ALB, Enc., cx. 50, cap. 3, cota antiga: M 40 N 24), o que indicia a existência de uma instituição de assistência anterior às aqui apresentadas ${ }^{37}$.

Retomando ainda o texto da instituição da capela de Manuel de Magalhães, este previa que, caso a Misericórdia fosse impedida de aceitar as verbas, as mesmas servissem para a fundação de um hospital em Ponte da Barca, de assistência a pobres e pessoas necessitadas dessa localidade e de Souto de Rebordões (e só depois de outras localidades), o qual devia ser administrado pelos homens bons da câmara da vila e chefiado por um «homem de boa consciência que tivesse carrego de administrar o sobredito» num mandato de três anos. Por esse trabalho seria remunerado «o que lhes bem parecesse por seu trabalho».

Apesar da intenção dos doadores, não temos referência (no $A L B$ ) de que o hospital tenha sido efetivamente construído.

\footnotetext{
${ }^{35}$ Cursou Cânones em Coimbra, entre 1582 e 1588 (Veloso, 1998: 98). No ALB, não existe documentação de Matias da Silva, ele é apenas referido em documentação respeitante ao morgado, como num acordo que António de Magalhães obteve acerca de duas terças do morgado. BNP, ALB, ANTT, cx. 19, doc. 27.

${ }^{36} \mathrm{Em}$ 1665, é Manuel da Silva de Meneses, abade de Santo André de Guilhadeses e sobrinho de Bento da Silva de Meneses, quem pede uma certidão em como o tio fora o administrador da capela de Manuel de Magalhães. BNP, ALB, Roma, cx. 81, n. ${ }^{\circ}$ 92, cap. 1, doc. n. n.

37 Possivelmente o mesmo a que alude Costa (1998: 107).
} 


\section{António de Magalhães e a fundação do hospital de peregrinos -1590}

Filho de Manuel de Magalhães e de Margarida da Silva, António de Magalhães (flor. $1549^{38}-1590^{39}$ ) casou cerca de $1570^{40}$ com Isabel de Meneses (flor. 1549 ${ }^{41}-1605^{42}$ ), sua prima, filha de Francisco de Magalhães e de Leonor Pereira, contra a vontade dos pais $^{43}$, que, como mencionámos, lhe retiraram a possibilidade de suceder na administração da capela que fundaram (BNP, ALB, Roma, cx. 81, cap. 1, doc. 1). Foram pais de Constantino de Magalhães e Meneses, casado com Isabel Manuel de Aragão44.

Em 1569, era escudeiro fidalgo (BNP, ALB, Roma, cx. 58, fl. 175), em 1574 (BNP, ALB, Roma, cx. 58, fl. 239), enviou um navio (à sua custa) numa armada a Tânger (BNP,ALB, Roma, cx. 58, fl. 282) e, no ano seguinte, participou em nova armada em companhia de seu tio D. Duarte ${ }^{45}$. Estava em Castela, preparado para embarcar para África como aventureiro, quando soube da morte de D. Sebastião (BNP, ALB, Roma, cx. 58, fl. 241). Entre 1587 e 1590, foi por diversas vezes solicitado a defender com homens e armas a costa portuguesa e africana (BNP, ALB, Roma, cx. 58, fls. 229, 233, 276, 280, 290). Em outubro de 1588, embarcou na armada contra Francis Drake, levando na sua companhia mais de 500 homens, entre vassalos e criados (BNP, ALB, Roma, cx. 58, fl. 182; nova certidão acerca do mesmo assunto no fl. 231).

O período que mediou a morte de D. Sebastião e a aclamação de Filipe I foi de extrema importância para a afirmação político-militar de António de Magalhães na região minhota.

\footnotetext{
${ }^{38}$ BNP, ALB, Roma, cx. 60, fls. 76-77.

${ }^{39}$ Costa, 1998: 191, doc. 21; BNP, ALB, Roma, cx. 58, fl. 326.

40 O noivo tinha então cerca de 21 anos. BNP, ALB, Roma, cx. 60, fls. 76-77.

${ }^{41}$ BNP, ALB, Roma, cx. 60, fls. 76-77.

42 Já falecida nesta data. BNP, ALB, Roma, cx. 59, fl. 241.

${ }^{43}$ Manuel de Magalhães e Margarida da Silva interditaram o filho na sucessão da capela de S. João da Barca por lhes ter desobedecido e casado contra a sua vontade com Isabel de Meneses. A cláusula de destituição por desobediência está sublinhada a vermelho em BNP, ALB, Roma, cx. 81, n. ${ }^{\circ}$ 92, cap. 1, doc. 1, fl. 4v. Por seu lado, Leonor Pereira, no testamento que redigiu em 1567, referiu-se também ao dote e casamento da filha Isabel de Meneses e da possibilidade de esta se casar contra a vontade da família. BNP, ALB, Enc., Cx. 39 , liv. 13 , fls. $12 \mathrm{v}$ - 13 .

${ }^{44}$ Filha de João Manuel de Meneses (flor. 1567-1578) e Iria de Sequeira (flor. 1567), neta materna de Gonçalo de Sequeira e Genebra da Noli e paterna de Fradique Manuel e Maria de Ataíde. BNP, ALB, Roma, cx. 59, fls. 400-402; Gaio (1941: 27). Faz ainda parte do ALB um contrato de dote para casamento de Constantino com Joana Machado, filha de Mécia de Melo e Francisco Machado, senhor de Entre Homem e Cávado, o qual fora casado com Maria da Silva, uma tia de Constantino. BNP, ALB, Roma, cx. 60, fls. 55-61.

${ }^{45} \mathrm{O}$ pedido foi inicialmente dirigido a Manuel de Magalhães, o qual, pela sua idade, delegou no filho. Devia enviar 30 homens de soldo e mantimento à sua custa pelo prazo de 3 meses. BNP, ALB, Roma, cx. 58, fl. 271.
} 
Em 1580, os pais e os irmãos ${ }^{46}$ mandaram chamar os juízes e oficiais da milícia de Ponte da Barca para aclamarem D. António rei de Portugal. Relata um documento dirigido ao conde de Lemos que se trancaram numa casa e que depois de levantarem a rei a D. António, um dos irmãos de António de Magalhães saiu com um estandarte pelas ruas da vila, o que levou algumas pessoas a «repunharem» a sua mãe e irmãos, dizendo que os queriam matar. António de Magalhães, que se encontrava em Ponte de Lima ${ }^{47}$, regressou à Barca e prestou menagem ao rei espanhol (BNP, ALB, Roma, cx. 58, fls. 246, 251), contra a vontade da família.

Após este acontecimento, acorreu a Monção, à sua custa e risco ${ }^{48}$, para apaziguar os numerosos conflitos decorrentes da questão da sucessão da coroa portuguesa, tendo sido nomeado seu capitão-mor (BNP, ALB, Roma, cx. 58, fl. $225^{49}$ ) e, posteriormente, capitão de Ponte de Lima (BNP, ALB, Roma, cx. 58, fl. 246v.; carta de nomeação de 23 de setembro de 1580 , fl. 295). Foi desta localidade que teve de fugir com a família para a Galiza, acompanhado de muitos casais e homens armados de sua casa ${ }^{50}$, após o conhecimento da tomada do Porto por D. António, Prior do Crato. Com a aclamação de D. Filipe no Porto, António de Magalhães regressou a Portugal na companhia do conde de Lemos, com homens e cavalos à disposição do monarca (BNP, ALB, Roma, cx. 58, fl. 252v.). Por morte do pai, foi-lhe confirmada, em 1581 (BNP, ALB, Enc., cx. 11A, n. ${ }^{\circ}$ 3, cap. 3, fl. 3; ANTT, Chancelarias régias, D. Sebastião e D. Henrique, liv. 45, fls. 221-221v.), a doação de Souto de Rebordões e da terra da Nóbrega, terra da qual também foi nomeado alcaide-mor do castelo, tendo tomado posse em 1583 (BNP, ALB, Roma, cx. 58, fls. 297, 304). Foi também capitão-mor da vila de Ponte da Barca e seu termo (BNP, ALB, Roma, cx. 58, fl. 246).

Afastado da administração da capela fundada pelos seus pais, fundou, com a sua esposa, em 1576, uma capela de invocação de Madre de

\footnotetext{
${ }_{46}$ Manuel de Magalhães, já debilitado, veio a falecer em 1581. BNP, ALB, Enc., cx. 11A, cap. 3, fl. 3; BNP, ALB, Roma, cx. 58, fls. 246v., 251v.-252, 257, 298.

47 Organizada por Luís de Brito, fronteiro-mor, em novembro de 1580, com a participação de representantes de outros locais, para discutirem a sucessão no reino português.

${ }^{48} \mathrm{Na}$ vila, chegou a ter 80 a 100 homens seus, entre arcabuzeiros e besteiros. BNP, ALB, Roma, cx. 58, fls. 246, 251-251v.

${ }^{49}$ No fl. 248, há um outro documento relativo ao mesmo assunto de entrega de Monção a D. Diogo Sarmento e ida de António de Magalhães para Badajoz.

${ }^{50}$ Acompanhado de 40 ou 50 arcabuzeiros. Desta situação dão conta várias testemunhas, como Diogo Fernandes, criado de António de Magalhães, morador em Ponte da Barca, Bartolomeu Velho, morador em Nogueira, termo de Ponte da Barca, João Rodrigues, Gonçalo Romeu e Manuel Rodrigues Cardoso, todos moradores em Ponte da Barca. BNP, ALB, Roma, cx. 58, fls. 246v., 252, 253, 255, 257v., 259v. e 264.
} 
Deus, na Quinta da Boavista «para nela poderem ouvir missa» (BNP, ALB, Roma, cx. 91A, n. ${ }^{\circ} 122$, cap. 1, cota antiga: M 38 N 57) e para a aquisição de bens para o morgadio (BNP, ALB, Roma, cx. 90A, n. ${ }^{\circ} 119$, cap. 2, cota antiga: M 38 N 6).

Após petição ao Papa Sisto V, António de Magalhães obteve, em 1590, do Papa Gregório XIV, uma bula para fundar e prover financeiramente um hospital na Barca com rendas de algumas quintas ${ }^{51}$ e do padroado ${ }^{52}$ de algumas igrejas, no valor de 400 ducados $^{53}$. Pretendia o fundador que nele se «gasalhassem» os pobres peregrinos que se encontrassem de passagem para Santiago de Compostela, de onde distavam 21 léguas. Na bula, refere-se ainda que o hospital se encontrava vinculado ao morgadio, pelo que o administrador deveria ser o seu sucessor - o seu filho Constantino de Magalhães e Meneses e os filhos deste, os quais tinham por obrigação providenciar e cuidar do edifício, da sua capela, dos leitos, das roupas, etc.

Tendo António de Magalhães falecido no mesmo ano de 1590 (Costa, 1998: 191, doc. 21; BNP, ALB, Roma, cx. 58, fl. 326), foi a sua viúva, Isabel de Meneses, quem terminou a edificação do hospital. Em 1592, já se encontrava construído, pelo que Isabel de Meneses e o filho Constantino tomaram a sua posse (BNP, ALB, Enc., cx. 11A, n. ${ }^{\circ}$ 3, cap. 1, doc. n. n.).

A instituição do hospital não foi, no entanto, pacífica. Logo em 1590, D. Jorge de Ataíde, o representante do episcopado de Braga em Madrid (Costa, 1998: 107), quis anular a anexação das rendas. Esta atitude não impediu a sua dotação, pelo que, em 1591, Isabel de Meneses dotou o hospital com 300 reais anuais procedentes das rendas da Quinta da Pousada, em S. Tomé de Vade (BNP, ALB, Enc., cx.11A, n. ${ }^{\circ}$ 3, cap.1, doc.n.n.; Costa, 1998:193, doc. 23), das rendas provenientes das igrejas de que tinha direito de apresentação, já mencionadas (BNP, ALB, Enc., cx. 11A, n. ${ }^{\circ}$ 3, cap. 1), ao que adicionou, em 1592, mais 200 cruzados do rendimento das Igrejas de S. Tomé de Vade, Souto de Rebordões, Paço Vedro e Santa Maria de Covas (BNP, ALB, Enc., cx. 11A, cap.1, doc.n. n.). No que se refere à capela que devia ser construída junto ao hospital ${ }^{54}$, foi também no ano de 1592 que a referida senhora tomou posse de parte do quintal de Gonçalo

\footnotetext{
${ }^{51}$ Como a quinta da Pousada. BNP, ALB, ANTT, cx. 13, doc. 1070.

52 Igrejas de S. Martinho de Paço Vedro e sua anexa S. João da Barca, S. Tomé de Vade e sua anexa Santa Maria de Covas, S. Salvador de Souto de Rebordões e sua anexa Santiago de Sampriz e Santo André de Gondomar. BNP, ALB, Roma, cx. 114I, n. ${ }^{\circ}$ 187, cap. 5, cota antiga: M 106 N 20.

${ }^{53}$ Concretamente, 100 ducados de ouro anuais de cada igreja e mais 300 ducados de dinheiro próprio do morgado. BNP, ALB, Roma, cx. 114I, n. ${ }^{0} 187$, cap. 5, cota antiga: M 106 N 20.

${ }^{54}$ As capelas faziam frequentemente parte das infraestruturas hospitalares (Sá, 1997: 35-36).
} 
Lopes para a construir, não sem alguma contestação por parte do proprietário, que alegou que Isabel de Meneses tinha mais locais onde o fazer. Revela ainda o documento que a senhora tinha o «hábito de tomar propriedades e estradas que the interessam sob pretexto de melhorias» (BNP, ALB, Enc., cx. 11A, cap. 1, doc. n. n.) e que na vila havia outro hospital (possivelmente o da Misericórdia) e que por isso se podia escusar. De nada the valeu.

Ainda em 1592, o procurador da Coroa pretendeu demolir o hospital, invocando que as igrejas anexas eram da coroa e que o morgado não o podia ter sem consentimento do rei, pelo que apresentou uma revogação de letras apostólicas por parte do conde de Tentúgal. $\mathrm{O}$ juiz ordenava ainda que Constantino de Magalhães devia requerer diante do papa a anulação da instituição do hospital. O morgado recorreu para o papa, alegando que o hospital fora erigido de acordo com o direito, o qual the permitiu que pudesse reservar 100 cruzados para a câmara. Para o bom sucesso da petição terá concorrido o parecer jurídico de Diogo Mendes Sereno, que reiterava que o morgado não devia ser obrigado a encerrar o hospital (BNP, ALB, Enc., cx. 11A, cap. 2, cota antiga: M 106 N 10). $O$ mesmo parecer sugeria ainda que, se Constantino não tivesse sucessor, o hospital reverteria para a corte, assim como as suas rendas, o que terá levado ao apaziguamento da questão. Em 1600, ainda existia, uma vez que foi dada quitação a Constantino de Magalhães de ter satisfeito as obrigações (BNP, ALB, Roma, cx. 103, cap. 7, doc. n. n.).

A última menção no ALB ao hospital é datada de 1627 , no testamento de Constantino de Magalhães e sua esposa Isabel Manuel de Aragão, no qual determinaram que se pretendiam sepultar no altar-mor da capela, onde já se encontravam sepultados os seus pais, junto à abóbada (Costa, 1998: 104-106).

\section{Os arquivos de família: fontes para o estudo das instituições assistenciais portuguesas}

Os arquivos de família permitem estudar a história das famílias e dos seus elementos e abrem novas perspetivas a um conhecimento mais aprofundado da história social e económica das elites de Antigo Regime com recurso a outras fontes que não as até ao momento utilizadas (arquivos públicos centrais e municipais) e que nos dão uma visão «parcial» da história. Como nos lembra Maria de Lurdes Rosa (2009), os arquivos de família permitem trazer para a História atores desconhecidos ou praticamente desconhecidos ou mesmo ignorados e, no seu conjunto, «possibilita[m] o questionamento de versões do processo histórico construídas, sobretudo ou apenas, a partir dos acervos dos corpos sociais mais “administralizados" e/ou mais representados nos arquivos do Estado nação» (pp. 36-37).

Os arquivos de família constituem ainda, pelos motivos atrás apresentados, uma fonte 
indispensável para o estudo de instituições assistenciais de iniciativa e administração de leigos (Marques, 1989: 32, 52-53; Rodrigues, 2013: 21; Costa, 1973: 278).

Como tem vindo a ser referido por diversos autores, a fundação de instituições assistenciais foi uma realidade em Portugal desde a Idade Média (Almeida, 1973: 39-57; Marques, 1989; Costa, 1973: 259; Araújo, 2016: 232ss.). No entanto, até ao momento, as fontes para o seu estudo resumiam-se aos documentos existentes nos fundos da coroa (Marques, 1989: 27-28, 81), de mosteiros (Marques, 1991: 17; Araújo, 2016: 232) e, posteriormente, nos arquivos das misericórdias (Costa, 1973: 290; Marques, 1989: 81; Sá, 1997: 51-52, 59-60; 1998; Abreu, 2004; Araújo, 2016: 232, 239-243) $)^{55}$.

Intrinsecamente ligado aos caminhos, à itinerância (Almeida, 1973: 46; Moreno, 1986: 77-90; Araújo, 2016: 235), o auxílio prestado aos caminhantes consistia, na sua generalidade, em providenciar alimentação, repouso, apoio sanitário e, inclusive, no caso de alguns mosteiros, o acesso a algumas enfermarias exteriores (Marques, 1989: 36, 57; 1991: 21). E se na Idade Média os peregrinos partilhavam o mesmo espaço que os enfermos (Sá, 1997:
28-29; Rodrigues, 2013: 49; Park, 1992: 59-90; Araújo, 2016: 235, 238), a diferenciação de espaços destinados a uns e outros começou a verificar-se na época moderna ${ }^{56}$, assim como as «formas de seleção, especialização de cuidados e, no caso dos hospitais para doentes, pela presença efetiva de físicos durante o tempo de cura» (Rodrigues, 2013: 49), decorrentes da distinção, pelo poder central, entre os conceitos de hospitalidade e cura de enfermos verificada nos finais do século XV (Park e Henderson, 1991: 164-188; Sá, 1998: 34).

No caso dos leigos, e especificamente na família Magalhães, a fundação efetuou-se na sequência da instituição de legados pios (Sá, 1997: 34, 39; Araújo, 2016: 234). Quer Manuel de Magalhães quer o seu filho António de Magalhães referem a intenção de doar parte dos seus rendimentos para a fundação de um hospital. $O$ último realça que serviria para «gasalhar peregrinos», tendo vinculado a sua administração ao morgadio que havia instituído com sua esposa. O objetivo de ambos era o mesmo - a salvação da alma dos instituidores por via de obras pias aos mais desfavorecidos - os pobres e os peregrinos (Sá, 1997: 35).

\footnotetext{
${ }^{55}$ Araújo (2016: 232, 239-243) chama a atenção para a falta de fontes nos arquivos de algumas Santas Casas (muitos destruídos devido a guerras como a da Restauração - no caso das Misericórdias de Monção, Valença, Melgaço e Valadares) e para a «incapacidade de destrinça entre despesas com pobres e com passageiros».

${ }^{56}$ Com exceção para o Hospital das Caldas, como referido por Sá (1997: 29; 1998: 44).
} 
Os hospitais fundados em Ponte da Barca no século XVI por estes dois elementos da família Magalhães e documentados no seu cartório familiar permitem, ainda, complementar com novos dados a rede de hospitais erigidos junto a vias portuguesas de peregrinação com destino a Santiago de Compostela, evidenciada por autores como Humberto Baquero Moreno (1986: 77-90) e Carlos Alberto Ferreira de Almeida (1973: 46). Pensamos tratar-se de um ponto de apoio alternativo ${ }^{57}$ à via que, partindo do Porto, passava por Braga, Ponte de Lima e Valença, e que passaria, possivelmente, pelo Mosteiro de Vila Nova de Muía, ali bem perto, o qual recebia desde há muito peregrinos jacobeus (Marques, 1991: 16).

\section{Conclusão}

Os arquivos de família permitem não apenas estudar a história das famílias e dos seus elementos, mas também obter um conhecimento mais aprofundado da história social das elites de Antigo Regime, da sua produção documental, assim como, no presente estudo, permitem trazer novos elementos para o conhecimento, instituição, administração e funcionamento de hospitais ou outras instituições de assistência.

Com efeito, foi a partir da inventariação de um arquivo de família e da análise da produção documental de uma das muitas famílias nele contidas que pudemos encontrar referências à fundação de dois hospitais em Ponte da Barca no século XVI por duas gerações da família donatária da vila. Se para Manuel de Magalhães não podemos ir para além da intenção de fundação de um hospital para auxílio de pobres, já para António de Magalhães, seu filho, pudemos recuperar a bula papal de fundação do hospital que pretendeu edificar em Ponte da Barca, assim como o documento que comprova que o seu filho, Constantino de Magalhães, tomou efetivamente posse do mesmo.

A inventariação e o estudo de arquivos de família, alguns ainda na posse dos seus proprietários, pode constituir, pela documentação, a maior parte das vezes inédita, uma fonte e um instrumento fundamentais para uma compreensão mais global da instituição de obras de assistência aos mais desfavorecidos em Portugal e na Europa pré-moderna.

\section{Bibliografia}

\section{Manuscrita}

Arquivo Nacional Torre do Tombo (ANTT), Arquivo do arquivo, n. ${ }^{\circ} 331$, cx. 146, proc. 91, Aquisição do arquivo Lencastre Bastos;

Arquivo Nacional Torre do Tombo (ANTT), Chancelarias régias, D. Fernando, liv. 1; D. Afonso V, liv. 10; D. João III, Liv. 16; D. Sebastião e D. Henrique, liv. 45; D. João V, liv. 9;

Arquivo Nacional Torre do Tombo (ANTT), Gavetas, gav. 10, mç. 8; gav. 13, mç. 4;

\footnotetext{
${ }^{57}$ Cf. o mapa entre as pp. 50-51 de Almeida (1973).
} 
Arquivo Nacional Torre do Tombo (ANTT), Genealogias manuscritas, 21-F-08, Genealogia de D. António de Lima;

Arquivo Nacional Torre do Tombo (ANTT), Instituto Superior das Bibliotecas e Arquivos, cx. 329, proc. 274;

Arquivo Nacional Torre do Tombo (ANTT), Leitura Nova, Além Douro, livs. 1 e 4;

Biblioteca Nacional de Portugal (BNP), Arquivo Almada e Lencastre Bastos (ALB), ANTT, cxs. 13, 19; Enc., cxs. 11A, 39, 50, 54B; Roma, cxs. 58, 59, 60, 76, 81, 81A, 90A, 91A, 99, 103, 113A, 114I;

\section{Impressa}

Abreu, J. G. (1910). Terra da Nóbrega: Notas históricas. O Instituto, 57: 370-377, 430-437, 502-508, 558-565, 632-640;

Almeida, C. A. F. (1973). Os caminhos e a assistência no Norte de Portugal. A pobreza e a assistência aos pobres na Península Ibérica durante a Idade Média. Atas das Jornadas Luso-Espanholas de História Medieval. FLUL. Lisboa. 1. ${ }^{\circ}$ vol.: pp. 39-57;

Araújo, M. M. L. (2016). Dar pousada aos peregrinos na Misericórdia de Braga durante a Idade Moderna. Em: A intemporalidade da Misericórdia: As Santas Casas Portuguesas: Espaços e tempos. Santa Casa da Misericórdia de Braga. Braga;

Borja de Aguinagalde, F. (2013). Archivos de Familia y Archivos domésticos Treinta años de experiencias. Edição de autor. S. L.;

Chancelarias portuguesas: D. Duarte. (1998). Org. João José Alves Dias (Vol. I, t. 2: 1435-1438). Centro de Estudos Históricos. Lisboa;

Chancelarias portuguesas: D. João I. (2005). Org. João José Alves Dias (Vol. II, t. 1: 1385-1392). Centro de Estudos Históricos. Lisboa;

Coelho, M. F. (1980). O instituto vincular, sua decadência e morte: Questões várias. Análise Social, 16 (61/62): 111-131;

Coelho, M. H. C. (1990). A terra e os homens da Nóbrega no século XIII. Em: Homens, espaços e poderes (séculos XI-XVI): Notas do viver social. Livros Horizonte. Lisboa;

Conceição, P. (1720). Allegaçam practica, \& juridica sobre a posse, e successam do titulo, e Casa da Feira, contra os senhores procuradores da coroa, \& infantado, a favor de D. Alvaro Pereyra Forjaz Coutinho. Na Officina de Mathias Pereyra da Sylva \& Joam Antunes Pedrozo. Lisboa Occidental;

Contamine, Ph. e Vissière, L. (eds.). (2010). Défendre ses droits, construire sa mémoire: Les chartriers seigneuriauX $X I I^{\mathrm{e}}-X X I^{\mathrm{e}}$ siècle. Actes du Colloque International de Thouars (8-10 juin 2006). Société de l'Histoire de France. Paris;

Costa, A. D. S. (1973). Hospitais e albergarias na documentação pontifícia da segunda metade do século XV. A Pobreza e a Assistência aos pobres na Península Ibérica durante a Idade Média: Atas das Jornadas Luso-Espanholas de História Medieval. FLUL. Lisboa. 1. ${ }^{\circ}$ Vol.: pp. 259-327;

Costa, A. J. (1998). Subsídios para a história da terra da Nóbrega e do concelho de Ponte da Barca (Vol. 2). Centro Cultural Frei Agostinho da Cruz e Diogo Bernardes. Ponte da Barca;

Cunha, M. S. e Monteiro, N. G. (2010). Aristocracia, poder e família em Portugal, séculos XV-XVIII. Em: M. S Cunha e J. Hernández Franco (orgs.). Sociedade, família e poder na Península Ibérica: Elementos para uma História Comparativa. Edições Colibri-CIDEHUS, Universidade de Évora/Universidade de Múrcia. Lisboa;

De Vivo, F. (2010). Ordering the Archive in Early Modern Venice (1400-1650). Archival Science, 10 (3): 231-248;

Duarte, L. M. (1996). Leonel de Lima: O bando e o barco. Revista Portuguesa de História, 31(1), 371-392;

Freire, A. B. (1905). Povoação de Entre Doiro e Minho no XVI secolo. Archivo Histórico Portuguez. 3: 241-273; 
Fuente, F. (2011). Miguel Pereira Forjaz: O organizador da luta contra Napoleão. Tribuna da História. Lisboa;

Gago, A. B. (2015). Index Geral do Cartorio do Illustrissimo e Excelentissimo Senhor Visconde de Villa Nova do Souto de El Rey. Em: M. L. Rosa e R. C. Head (eds.). Rethinking the Archive in Pre-Modern Europe: Family Archives and Their Inventories from the $15^{\text {th }}$ to the $19^{\text {th }}$ century. IEM. Lisboa;

Gago, A. B. (2019). Arquivos e práticas arquivísticas de famílias de elite: Portugal, séculos XV-XVII. Tese de Doutoramento em História, especialização em Arquivística Histórica. Faculdade de Ciências Sociais e Humanas, Universidade Nova de Lisboa. Lisboa;

Gaio, M. F. (1938-1941). Nobiliário de famílias de Portugal. Agostinho de Azevedo Meirelles: Domingos de Araújo Affonso, (T. 19: 1939). [Pax. Braga];

García Aser, R. e Lafuente Úrien, A. (2000). Archivos Nobiliarios, cuadro de clasificación: Sección Nobleza del Archivo Histórico Nacional. Ministerio de Educación, Cultura y Deporte. Madrid;

Góis, D. (2014). Livro de linhagens de Portugal. Introd. e transcrição paleográfica de António Maria Falcão Pestana de Vasconcelos. Instituto Português de Heráldica, Universidade Lusíada. Lisboa;

Gómez Vozmediano, M. F. (2007). Archivos nobiliários españoles: Pasado, presente y ¿futuro? Tipología documental e investigación modernista. Em: F. Andújar Castillo e J. P. Díaz López (coord.). Los señoríos en la Andalucía Moderna: El Marquesado de los Vélez. Instituto de Estudos Almerienses. Almeria;

Head, R. C. (2007). Mirroring Governance: Archives, Inventories and Political Knowledge in Early Modern Switzerland and Europe. Archival Science, 7 (4), 317-329;

Leme, M. (2018). Costas com Dom: Família e arquivo (séculos $X V$ - $X V I I)$. Tese de Doutoramento em História, especialização em Arquivística
Histórica. Faculdade de Ciências Sociais e Humanas, Universidade Nova de Lisboa. Lisboa;

Livro de linhagens do século XVI. (1956). Int rod. pelo académico correspondente António Machado de Faria. Academia Portuguesa de História. Lisboa;

Marques, J. (1989). A assistência no Norte de Portugal nos finais da Idade Média. Revista da Faculdade de Letras: História, 2 (6): 11-93;

Marques,J.(1991). A assistência aos peregrinos, no Norte de Portugal, na Idade Média. Revista de História da Faculdade de Letras. 11: 9-22;

Mattoso, J. (1985). Ricos-homens, infanções e cavaleiros: A nobreza medieval portuguesa nos séculos xi e xii (2. ${ }^{a}$ ed.). Guimarães. Lisboa;

Monteiro, N. G. (2001). Trajectórias sociais e formas familiares: o modelo de sucessão vincular. Em: F. C. Jiménez e J. Hernández Franco (eds.). Familia, poderosos y oligarquías. Universidad de Murcia. Murcia;

Moreno, H. B. (1980). A Batalha de Alfarrobeira: Antecedentes e significado histórico. Biblioteca Geral da Universidade. Coimbra. Vol. 2;

Moreno, H. B. (1986). Vias portuguesas de peregrinação a Santiago de Compostela na Idade Média. Revista da Faculdade de Letras: História, 2 (3): 77-90;

Morsel, J. (2008). Du texte aux archives: Le problème de la source. Bulletin du Centre d'Études Médiévales d'Auxerre. Hors série n. ${ }^{\circ} 2$;

Nóvoa, R. L. S. (2016). O Arquivo Gama Lobo Salema e a produção, gestão e usos dos arquivos de família nobre nos séculos XV-XVI. Tese de Doutoramento em História, especialização em Arquivística Histórica. Faculdade de Ciências Sociais e Humanas, Universidade Nova de Lisboa. Lisboa;

Park, K. (1992). Medicine and Society in Medieval Europe, 500-1500. Em: A. Wear (ed.). Medicine in Society: Historical Essays. Cambridge University Press. Cambridge; 
Park, K. e Henderson, J. (1991). The First Hospital Among Christians: The Ospedale di Santa Maria Nuova in Early Sixteenth Century Florence. Medical History. 35: 164-188;

Páscoa, M. (2015). O códice 702: Um cartulário de D. Jaime de Bragança. Fundação Casa de Bragança;

Pereira, M. D. S. (2008). Entre ricos e pobres: A actuação da Santa Casa da Misericórdia de Ponte da Barca (1630-1800). Santa Casa da Misericórdia. Ponte da Barca;

Pinto, P. (2012). O Arquivo da Família Almada Lencastre Basto (Casa de Souto de El-Rei e Casa da Feira) na Biblioteca Nacional: Propostas de exploração no âmbito da elaboração de um catálogo. Em: M. L. Rosa (org.). Arquivos de família, séculos XIII-XX: Que presente, que futuro? Instituto de Estudos Medievais, Centro de História de Além-Mar e Caminhos Romanos. Lisboa;

Portugaliae Monumenta Historica a saecvlo octavo post christvm vsque ad qvintvmdecimvm ivssv academiae scientiarvm olisiponesis - Inquisitiones: Inquirições gerais de D. Dinis 1288: Sentenças de 1290 e execuções de 1291 (Vol. 4). (2012). Introd., leitura e índices de J. A. de S. M. Pizarro. Imprensa Nacional-Casa da Moeda, Academia das Ciências de Lisboa. Lisboa;

Portugaliae Monumenta Misericordiarum: Reforço da interferência e elitização: o governo dos Filipes (vol. 5). (2006). Dir. de L. Abreu e J. P. Paiva. Ed. lit. do Centro de Estudos de História Religiosa da Faculdade de Teologia. União das Misericórdias Portuguesas. Lisboa.

Rodrigues, A. e Silva, A. M. (2012). A criação das Gavetas na Casa de Mateus: Um modelo iluminista de gestão da informação. Em: M. L. Rosa (org.). Arquivos de família, séculos XIII-XX: Que presente, que futuro? Instituto de Estudos Medievais, Centro de História de Além-Mar e Caminhos Romanos. Lisboa;

Rodrigues, L. O. (2013). Os hospitais portugueses no Renascimento (1480-1580): O caso de Nossa Senhora do Pópulo das Caldas da Rainha. Tese de Doutoramento em História, especialidade de História Moderna. Instituto de Ciências Sociais, Universidade do Minho. Braga;

Rosa, M. L. (2009). Problemáticas históricas e arquivísticas actuais para o estudo dos arquivos de família portugueses; Épocas medieval e moderna. Revista de História da Sociedade e da Cultura. 9: 9-42;

Rosa, M. L. (2012). Os espelhos e os seus outros lados: Inventários e gestão da informação documental do Viscondado de Vila Nova de Cerveira/Marquesado de Ponte de Lima e família Brito-Nogueira, séculos XV-XIX. Em: M. L. Rosa (org.). Arquivos de família, séculos XIII-XX: Que presente, que futuro? Instituto de Estudos Medievais, Centro de História de Além-Mar e Caminhos Romanos. Lisboa;

Rosa, M. L. (2017). Reconstruindo a produção, documentalização e conservação da informação organizacional pré-moderna: Perspetivas teóricas recentes e proposta de percurso de investigação. Boletim do Arquivo da Universidade de Coimbra. 30: 547-586;

Sá, I. G. (1997). Quando o rico se faz pobre: Misericórdias, caridade e poder no Império Português: 1500-1800. Comissão Nacional para as Comemorações dos Descobrimentos Portugueses. Lisboa;

Sá, I. G. (1998). A reorganização da caridade em Portugal em contexto europeu (1490-1600). Cadernos do Noroeste, 11 (2): 31-63;

Silva, A. M. (1997). Arquivos de família e pessoais: Bases teórico-metodológicas para uma abordagem científica Em: Arquivos de Família e Pessoais: Seminário. APBAD. Vila Real;

Silva, I. M. S. (1997). A Ordem de Cristo durante o mestrado de D. Lopo Dias de Sousa (1373?-1417). Em: Militarium Ordinum Analecta: As ordens militares no reinado de D. João I. 1: 21-120;

Silva, J. M. (1917). Vila Nova de Souto de El Rey (Francisco de Almada e Mendonça, Visconde de). Revista de Ex-Libris Portugueses. 10: 146-152; 
Silva, J. P. M. (2010). A Ordem de Cristo durante o Mestrado de D. Nuno Rodrigues Freire de Andrade (1357-1372). Dissertação de Mestrado em História Medieval. Faculdade de Letras, Universidade de Lisboa. Lisboa;

Sousa, A. C. (1742). Livro dos moradores da casa do Senhor Rey D. João III do nome, Rey de Portugal. Provas da História Genealógica da casa Real Portugueza.... (T. II). Officina Sylviana. Lisboa;

Sousa, M. J. O. F. C. C. A. (2017). O Arquivo da casa de Belmonte, séculos XV-XIX: Identidade, gestão e poder. Tese de Doutoramento em História, especialização em Arquivística Histórica. Faculdade de Ciências Sociais e Humanas, Universidade Nova de Lisboa. Lisboa;

Veloso, M. T. N.(1998). Ponte-Barquenses na Universidade de Coimbra. Subsídios para a história da terra da Nóbrega e do concelho de Ponte da Barca. Comunicações apresentadas no Seminário «Da terra da Nóbrega ao concelho de Ponte da Barca». Centro Cultural Frei Agostinho da Cruz e Diogo Bernardes. Ponte da Barca. 2. ${ }^{\circ}$ Vol.: pp. 93-115;

Villas Boas, M. (1998). Os Magalhães: Sete séculos de aventura. Estampa. Lisboa.

\section{Digital}

Abreu, L. (2004). Igreja, caridade e assistência na Península Ibérica (sécs. XVI-XVIII). Em: Abreu, L. (dir.) Igreja, caridade e assistência na Península Ibérica (sécS. XVI-XVIII). CIDEHUS. Évora. Acedido em 20 de Agosto de 2019, em: https://books. openedition.org/cidehus/182;

Morsel, J. (2013). Histoire ou passé? L’archivage comme problème pour l'intelligence historique de la société médiévale. Archifam - Les archives de famille: Formes, histoires et sens d'une genèse (XIV-XVII siècle). 2013. Acedido a 20 de agosto 2019, em: https:// www.casadevelazquez.org/fileadmin/fichiers/investigacion/Epoque_antique_medievale/2013-2014/Morsel_texteHistoire_ou_ pass\%C3\%A9_4mars2013.pdf;

Santa, N. V.(2018). Do Algarve ao Império e à titulação: Estratégias de nobilitação na Casa dos Barretos da Quarteira (1383-1599) [Versão eletrónica]. Revista Maracanan, 19: 12-35. Acedido em 20 de agosto 2019, em: https://run.unl.pt/ bitstream/10362/42885/1/33247_120473_1_ PB.pdf;

Soveral, M. A. (s. d.) Ensaio sobre as origens dos Magalhães. Acedido a 20 de agosto de 2019, em: http://www.soveral.info/mas/Magalhaes.htm. 